\title{
Immunocytokine NHS-IL12
}

National Cancer Institute

\section{Source}

National Cancer Institute. Immunocytokine NHS-IL12. NCI Thesaurus. Code C97961.

A fusion protein consisting of the heavy-chains of the human antibody NHS76, raised against DNA released by necrotic tumor cells, and fused to two molecules of a genetically modified human interleukin-12 (IL-12) with potential immunostimulating and antineoplastic activities. Upon administration, the antibody moiety of immunocytokine NHS-IL12 binds to DNA released from necrotic tumor cells located primarily at the core of necrotic solid tumors, thereby delivering the IL-12 moiety. In turn, the IL-12 moiety of this agent stimulates the host immune system to mount an immune response against tumor cells, thereby inhibiting tumor growth. IL-12 is a proinflammatory cytokine with numerous immunoregulatory functions and may augment host immune responses to tumor cells. By targ eting tumor cells, NHS-IL-12 may reduce the toxicity associated with systemic administration of recombinant human IL-12. 